\title{
Bacterial pseudomycosis: a rare cause of haemoptysis
}

\author{
A.S. Multz*, R. Cohen**, V. Azeuta
}

Bacterial pseudomycosis: a rare cause of haemoptysis. A.S. Multz, R. Cohen, V. Azeuta. CERS Journals Ltd 1994.

ABSTRACT: Pulmonary bacterial pseudomycosis, also referred to as botryomycosis, is a very rare, indolent illness that has been described mostly in patients with immunological problems. The histological appearance is similar to that of actinomycosis; however, various Gram-positive and Gram-negative bacteria have been implicated in the pathogenesis.

We illustrate a rapidly progressive case of pulmonary bacterial pseudomycosis in a normal host whose presenting complaint was haemoptysis. Eur Respir J., 1994, 7, 1712-1713.

*Dept of Medicine, Division of Pulmonary and Critical Care Medicine, LIJ-Queens Hospital Center, Albert Einstein College of Medicine, New Hyde Park, NY, USA. **Dept of Medicine, Pulmonary and Critical Care Medicine, LIJ-Medical Center, New Hyde Park, NY, USA. †Dept of Pathology, LIJ-Queens Hospital Center, The City University of the New York Medical School, Jamaica, NY, USA.

Correspondence: A.S. Multz

Division of Pulmonary and Critical Care Medicine, Long Island Jewish Medical Center, 270-05 76th Avenue, New Hyde Park, NY 11042, USA.

Keywords: Bacterial pseudomycosis, botryomycosis, haemoptysis

Received: September 13 1993. Accepted after revision April 11994

Bacterial pseudomycosis is a rare, chronic disease, whose aetiology may be infectious. This disease has been reported to occur in many organ systems, including skin, muscle, bone and viscera [1-2]. In the skin, the disease grossly resembles a mycetoma. The lung is rarely a primary location of this disease, but primary pulmonary bacterial pseudomycosis has been described in patients with underlying immunological defects [3-6].

In the lungs, pseudomycosis has histological characteristics similar to actinomycosis. It is, therefore, necessary to make the appropriate distinction between the two, because of the difference in treatment modalities. Pseudomycosis is frequently resistant to routine antibacterial treatment, and, surgical intervention may be necessary for complete resolution of the problem. Bacteria associated in the pathogenesis of this disease include Staphylococcus aureus, Streptococcus pneumoniae, Escherichia coli, Proteus spp. and Pseudomonas aeruginosa $(1,3,5]$. The case presented here illustrates a rapid clinical course, without the indolent pattern seen in previously described cases of primary pulmonary bacterial pseudomycosis.

\section{Case report}

A 66 year old woman, without a significant past medical history, presented to our institution with a 10 day history of haemoptysis. This was described as small amounts of gross blood without any purulent secretions. She had been seen 10 days prior to her admission in her native country, the Dominican Republic, was initially told that she had a pulmonary infarct, and was antico- agulated. When the haemoptysis did not resolve, the anticoagulation was discontinued and the patient was taken by family members to our institution for evaluation. The only pertinent historical information was a 5 $\mathrm{kg}$ weight loss over the previous 10 months. The patient denied any history of smoking or alcohol use. Physical examination revealed no abnormalities and the patient was afebrile. A chest radiograph showed an extensive infiltrate in the right upper lobe, with a suggestion of cavity formation. When compared with a previous film taken 10 days earlier, that the patient had brought with her, there was a significant enlargement of the involved area of lung parenchyma. No radiographic evidence of pleural effusion was noted. Laboratory studies revealed a white blood count of $7.8 \times 10^{9} \cdot l^{-1}$ with a normal differential. The haematocrit was $34 \%$. A co-agulation profile was within normal limits. Room air arterial blood gas showed an arterial oxygen tension $\left(\mathrm{PaO}_{2}\right)$ of $10 \mathrm{kPa}(76 \mathrm{mmHg})$ and no evidence of carbon dioxide retention. Spirometry showed all values to be greater than $80 \%$ of predicted and flow volume loop revealed a normal contour. Serum lactate dehydrogenase was slightly elevated to $275 \mathrm{U} \cdot l^{-1}$ and alkaline phosphatase was also minimally elevated to $126 \mathrm{U} \cdot l^{-1}$. Sputum culture revealed normal mouth flora and the sputum cytology was negative. A purified protein derivative (tuberculin) (PPD) was negative, with a positive response to anergy panel testing. Sputum for acid-fast bacilli was also negative. A CD4/CD8 count and ratio were normal, as were serum protein electrophoresis and quantitative immunoglobulin assays.

There was worsening of the radiographic infiltrate, 


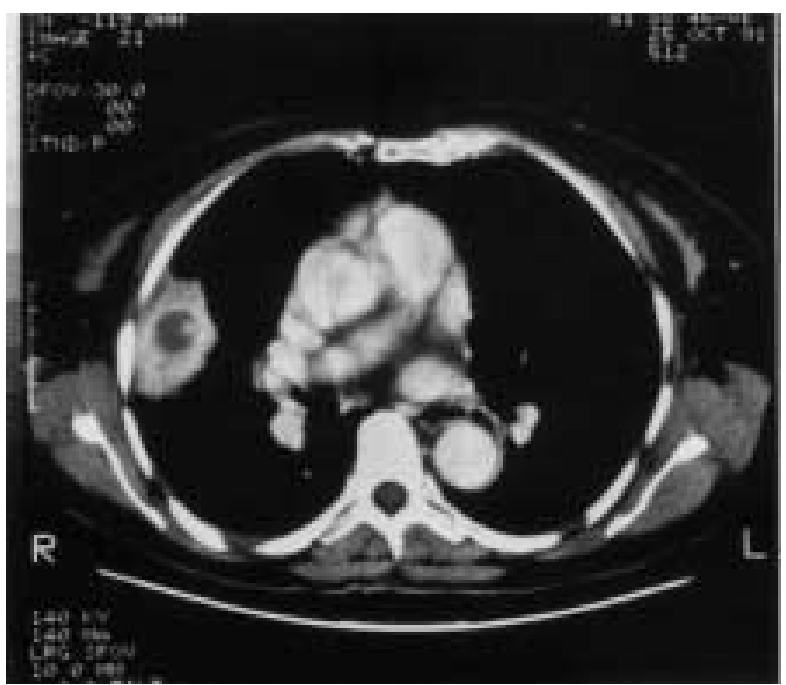

Fig. 1. - Computed tomographic (CT) scan of the chest showing a large right upper lobe mass. An area of breakdown is seen in the centre of the mass.

despite treatment with intravenous clindamycin and ceftriaxone. The patient underwent a computed tomographic (CT) scan of the chest (fig. 1), which revealed a mass with an area of central breakdown. Fibreoptic bronchoscopy showed inflammation in the right upper lobe area, but no endobronchial pathology was found. Cytological studies were negative. Cultures and smears of the washings for acid-fast bacilli and fungi were negative. Thoracotomy was recommended, and on day 14 the patient underwent a right upper lobectomy.

Gross examination revealed multiple abscesses filled with soft tan and haemorrhagic material within an area of consolidation involving mainly the anterior segment of the lobe. Microscopically, (fig. 2), the abscesses contained purulent exudate, blood and masses resembling "sulphur granules" of actinomycosis. The granules consisted of Gram-positive coccal and bacillary

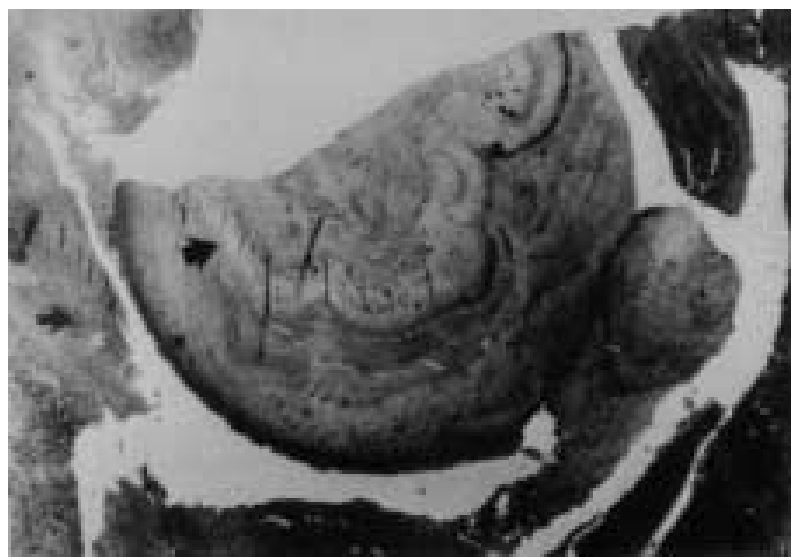

Fig. 2. - Sections through an abscess showing chronic necrotizing granulomatous inflammation (large arrow), and surrounding normal lung tissue (small arrow). (Haematoxylin and eosin stain. Magnification $\times 10$ ). bacterial colonies within eosinophilic, hyaline material. Special cultures and stains for Actinomyces, fungi and acid-fast bacilli were negative. The walls of the abscesses consisted of chronically inflamed granulation and fibrous tissue. Beyond the abscesses, areas of acute and areas of chronic and organizing pneumonia were present. The patient's postoperative course was unremarkable, and she was discharged six days later. Antibiotics were continued for two weeks after discharge, and she continued to do well on follow-up visits.

\section{Discussion}

Bacterial pseudomycosis was originally described in the skin of stallions in 1870 [7]. In humans, it usually involves skin and subcutaneous tissue. Visceral involvement is rare. Lung involvement has been reported in occasional abscesses in immunologically deficient hosts, as in patients with chronic granulomatous disease $[5,6$, 8]. In the majority of cases, the lesions present as multiple or single abscesses or chronic suppurative bronchiectasis. The abscesses contain colonies of bacteria enclosed within hyaline coating (Splendore-Hoeppli reaction) [9] bearing a resemblance to the sulphur granules of actinomycosis. The eosinophilic "clubbing" material is an antigen-antibody complex [7]. The granules may vary in size from microscopic to grossly detectable particles. The surrounding reaction to the infection varies from purulent exudate enclosed by chronically inflamed granulation tissue or fibrosis to a purely granulomatous reaction $[5,8]$. It is obvious that since the process appears to be related to infection with common bacterial species, its resemblance to actinomycosis requires careful studies, as were performed in this case, to rule out actinomycetes as the aetiological agent.

This patient demonstrates a rapid radiographic and clinical progression of primary pulmonary bacterial pseudomycosis; a disease usually associated with a slow progression. This illness should be considered in patients without chronic illness who present with cavitary lung disease.

\section{References}

1. Winslow DJ. Botryomycosis. Am J Pathol 1959; 35: 153167.

2. Winslow DJ, Chamblin SA. Disseminated visceral botryomycosis. Am J Clin Pathol 1960; 33: 43-47.

3. Greenblatt M, Heredia R, Rubenstein L, et al. Bacterial pseudomycosis (botryomycosis). Am J Clin Pathol 1964; 41: 188-193.

4. Speir WA, Mitchener JW, Galloway RF. Primary pulmonary botryomycosis. Chest 1971; 60(1): 92-93.

5. Katznelson D, Vawter GF, Foley GE, et al. Botryomycosis, a complication of cystic fibrosis: report of 7 cases. J Pediatr 1965; 65: 525-539.

6. Paz HL, Little BJ, Ball Jr WC, et al. Primary pulmonary botryomycosis. Chest 1992; 101: 1160-1162.

7. Spencer $\mathrm{H}$ (ed.). In: Pathology of the Lung. 4th edn. London, Pargamon Press, 1985; pp. 267-269.

8. Thurlbeck WM (ed.). In: Pathology of the Lung. New York, Thieme, 1988; pp. 214-215.

9. Dail DH, Hammer SP (eds.). In: Pulmonary Pathology, New York, Springer Verlag, 1988; pp. 160-162. 